need to deal with the problem of osteoporosis. Ideally, we should identify the most vulnerable women at the menopause and reduce the physiological decline in bone mineral, without undue risk to other systems. There is interest in ultrasound screening. ${ }^{20}$ Further studies may show that measurement of ultrasonic attenuation through the os calcis, although lacking the precision of low dose radiation techniques, may be able to identify women at greatest risk of later sustaining a hip fracture.

This study was made possible by the financial support of the Department of Health. We are grateful for the cooperation of the Department of Social Services; Yorkshire Regional Health Authority locally organised research scheme; the geriatricians, orthopaedic surgeons, and medical physics departments in Doncaster and Hull; and for the secretarial help of Mrs Jean Reynolds.

1 Royal College of Physicians. Fractured neck of femur. Prevention and management. London: RCP, 1989.

2 Bulstrode C. Keeping up with orthopaedic epidemics. Br Med f 1987;295:514 3 Cooper C, Barker DJP, Morris J, Briggs RSJ. Osteoporosis, falls, and age in fracture of the proximal femur. Br Med $\mathcal{F}$ 1987;295:13-5.

4 Consensus Development Conference. Prophylaxis and treatment of osteoporosis. Br Med F 1987;295:914-5.

Aitken JM. Relevance of osteoporosis in women with fracture of the femora neck. Br Med f 1984;288:597-601.
6 Langton C McD, Palmer SB, Porter RW. Measurement of broadband ultrasonic attenuation in cancellous bone. Eng Med 1984;13:89-91.

7 Porter RW, Johnson K, McCutchan JDS. Colles fracture, BUA and thoracic kyphosis. Bone (in press).

8 Pattie AH, Gilleard CJ. The two year predictive validity of the Clifton assessment schedule and the shortened Stockton geriatric rating scale. Brf Psychiatry 1978;133:457-60.

9 Palmer SB, Langton C McD. Ultrasonic studies of bone. London: Institute of Physics, 1987. (Short meetings series No 6).

10 Baran DT, Kelly AM, Karellas A, et al. Ultrasonic attenuation of the os calcis in women with osteoporosis and hip fractures. Calcif Tiss Int 1988;43. $138-42$

11 Wasnich RD, Ross PD, Heilbrun LK, Vogel JM. Selection of the optima skeletal side for fracture risk prediction. Clin Orthop 1987;216:262-8.

12 Cook PJ, Exton-Smith AN, Brocklehurst JC, Lempert-Barber SM. Fracture femur, falls and bone disorders. $\mathcal{F} R$ Coll Physicians Lond 1982;16:45-9.

13 Horsman A, Nordin BEC, Simpson M, Speed R. Cortical and trabecular bon status in elderly women with femoral neck fracture. Clin Orthop 1982;166: 143-51.

14 Cooper C, Barker DJP, Morris J, Briggs RSJ. Osteoporosis, falls and age in fracture of the proximal femur. Br Med 7 1987;295:13-5.

15 Sher JL, Aird EGA. A photon absorbtiometric estimation of bone minera content in the proximal femur. F Bone foint Surg [Br] 1983;65:660.

16 Boyce WJ. Osteoporosis, falls, and age in fracture of the proximal femur. BrMed f 1987;295:444-5.

17 Boyce WJ, Vessy MP. Rising incidence of fracture of the proximal femur. Lancet 1985;i:150-1.

18 Melton KLJ, O'Fallon WM, Riggs BL. Secular trends in the incidence of hip fractures. Calcif Tiss Int 1987;41:57.

19 Schapira AHV. Visual disability and the elderly. Time for general practitioners to begin preventive screening. Br Med F 1989;298:1126-7.

20 Anonymous. Ultrasound and bone fragility [Editorial]. Lancet 1989;ii:842.

(Accepted 10 fuly 1990)

\title{
Four and a half year follow up of women with dyskaryotic cervical smears
}

\author{
Astrid Fletcher, Nikki Metaxas, Chandra Grubb, Jocelyn Chamberlain
}

Department of Community Medicine, University College Hospital Medical School, London

Astrid Fletcher, PHD, research fellow

Jocelyn Chamberlain, FRCP, senior lecturer

Joint Royal Free Hospital and University College Hospital Department of Cytology, London

Nikki Metaxas, MD, clinical assistant

Chandra Grubb, MRCPATH, director

Correspondence to: Dr A Fletcher, Epidemiology Research Unit, Division of Geriatric Medicine, Department of Medicine, Royal

Postgraduate Medical

School, London W12 0HS

BrMed f 1990;301:641-4 colposcopy — needs to be determined by randomised controlled trials.

Objective-Todetermine the proportion of women with mild or moderate dyskaryosis in cervical smears who $(a)$ progress to cervical intraepithelial neoplasia grade III or worse or $(b)$ regress.

Design-Four and a half year cytological follow up study of women with mild or moderate dyskaryosis in cervical smears.

Setting-A cytology laboratory in inner London.

Patients-666 Women (mean age 28 (SD 8) years; range 14-74) found to have borderline, mild, or moderate dyskaryosis on routine screening.

Results-45 Women (6.8\%) had a cone biopsy recommended on the basis of an abnormal follow up smear (severe dyskaryosis suggestive of cervical intraepithelial neoplasia grade III or invasive cancer), and in one patient cervical intraepithelial neoplasia grade III was reported in a biopsy specimen after dilatation and curettage. Life table analysis gave a $14 \%$ probability of a patient being recommended for a biopsy after four and a half years of follow up $(\mathbf{9 5 \%}$ confidence interval $12 \%$ to $15 \%$ ). There was a significant excess incidence of invasive cancer of the cervix in the series compared with the general population (five cases observed compared with less than 0.1 expected). 157 Patients (24\%) showed reversion to a normal cell pattern sustained in several smears over more than 18 months but a single negative smear was an unreliable indicator of apparent regression. Having two successive smears showing mild dyskaryosis or a smear at any time showing moderate dyskaryosis was a significant predictor of a subsequent severely dyskaryotic smear.

Conclusions-Women found to have mild or moderate dyskaryosis in cervical smears should be kept under regular surveillance. The optimum management of these patients-by cytology or

\section{Introduction}

Guidelines have been published for the management of mild cervical intraepithelial abnormalities (cervical intraepithelial neoplasia grades I and II) detected in cervical smears ${ }^{1-3}$ Singer recommended colposcopy for all women with smears showing mild to severe cervical squamous dyskaryosis or malignant cells. ${ }^{1}$ Fox endorsed this approach but acknowledged that the extra burden on resources might not allow it. ${ }^{2}$ If immediate colposcopy was not available a repeat smear in three to six months was recommended with subsequent referral for colposcopy and biopsy for any dyskaryosis no matter how mild. Fox concluded: "Compromise is inevitable with inadequate colposcopy services in Britain, but compromise may sometimes mean death." The impetus for that comment was a report of 14 cases of cervical cancer in young women with previous dyskaryotic smears. ${ }^{3}$ Tragic as those cases were, however, they do not constitute the scientific evidence required for guidelines.

The report of the Intercollegiate Working Party on Cervical Cytology Screening also suggested colposcopy, ideally for all women with dyskaryotic smears but immediately for moderate dyskaryosis and after a further dyskaryotic follow up smear for mild dyskaryosis. ${ }^{4}$ Some contradictions were evident in that report, however, which suggested immediate colposcopy as an ideal but also stated that the optimum management of mild or moderate dyskaryosis was not known.

The outcome for patients with dyskaryotic smears is contentious. Studies have shown considerable variation in the proportions who seemed to show neoplastic progression or spontaneous reversion to normal and 
differing predictors of outcome. ${ }^{5-12}$ Differences in criteria for admission, methods, and duration of follow up among studies may partly account for these variations. The methodological problems in designing a study to determine the natural course of cervical neoplasia are formidable. Cytological or colposcopic diagnosis can only suggest the underlying histological lesion, estimated rates of agreement varying from $69 \%$ to $93 \%$ for cervical intraepithelial neoplasia grade III or invasive cancer but being lower for cervical intraepithelial neoplasia grades I and II. ${ }^{1314}$ Punch biopsy samples are likely to affect the course of the lesion $^{15}$ and may be incomplete. Interobserver and intraobserver variations are a well known source of error.

We have followed up a cohort of women with dyskaryotic smears to determine their outcome. In all cases smears were suggestive of cervical intraepithelial neoplasia grades I and II or milder abnormalities, and patients had not had colposcopy. This paper presents the results of the first four and a half years of the study, when the women were under intensive cytological surveillance. We hope that the cohort may be registered with the Office of Population Censuses and Surveys for cancer registration in order to provide valuable long term information on the incidence of and mortality from cancer of the cervix.

\section{Study population and methods}

The study population was drawn from all women whose smears had been screened at the joint cytology department of the Royal Free and University College Hospitals over three years. The laboratory day books for a two year period were checked retrospectively and initially 762 patients selected on the basis of a report of cellular abnormality. A further 225 patients were identified prospectively, over one year. All smears were reviewed, firstly, by NM, then by CG, and jointly when interpretation differed.

Three hundred and twenty one patients $(33 \%)$ were excluded: 100 had had a previous abnormal smear and in 204 the smears were considered on review not to show evidence of relevant cellular abnormality; private patients (17) were also excluded. The final total included in the study was 666 women. Demographic details of patients at entry were derived from the cytology request form. Social class was coded by husband's occupation for married and widowed women and by own occupation for single, separated, and divorced women. ${ }^{16}$

Classification of smears-Smears were classified as borderline dyskaryosis, either with inflammatory changes $(n=169 ; 25.4 \%)$ or without inflammatory

TABLE I-Classification of dyskaryosis in initial cervical smears from women distributed by age

\begin{tabular}{lrrrrr}
\hline & \multicolumn{4}{c}{ Age group (years) } & \\
\cline { 2 - 5 } Classification of initial smear & $\leqslant 24$ & $25-34$ & $35-44$ & $\geqslant 45$ & Total \\
\hline Borderline only & 16 & 10 & 6 & 2 & 34 \\
Borderline plus inflammatory & 55 & 82 & 20 & 12 & 169 \\
Mild & 173 & 186 & 49 & 16 & 424 \\
Moderate & 8 & 20 & 10 & 1 & 39 \\
\hline Total & 252 & 298 & 85 & 31 & 666 \\
\hline
\end{tabular}

TABLE II-Cytological and histological findings in 45 women recommended for biopsy

\begin{tabular}{lcccccr}
\hline & \multicolumn{4}{c}{ Histological finding } \\
\cline { 2 - 5 } & & \multicolumn{2}{c}{ Cervical intraepithelial neoplasia } & \\
\cline { 2 - 5 } Cytological report & Cancer of cervix & Grade III & Grade II & Grade I & Total \\
\hline Cancer of cervix & 4 & 31 & 4 & 5 & 41 \\
\hline Cervical intraepithelial neoplasia grade III & 1 & 31 & 4 & 5 & 45 \\
\hline Total & 5 & & & & 4 \\
\hline
\end{tabular}

changes $(n=34 ; 5 \cdot 1 \%)$; mild dyskaryosis $(n=424$; $63 \cdot 7 \%)$; and moderate dyskaryosis $(n=39 ; 5 \cdot 9 \%)$ (see table I). All smears were additionally coded as adequate or inadequate. The criterion for an adequate smear was the presence of a sufficient number of squamous cells, endocervical columnar cells, or metaplastic squamous cells to show that the squamocolumnar junction or the transformation zone had been sampled. ${ }^{17}$

Follow up - The interval at which a repeat smear was requested depended on the classification of each smear. Repeat smears were requested at six months for borderline and inflammatory dyskaryosis. For mild dyskaryosis a first repeat smear was requested at three months, and if this was normal or showed borderline or persistent mild dyskaryosis further smears were requested at six months. For moderate dyskaryosis a repeat smear was requested at three months. If a repeat smear was negative further smears were requested until three consecutive negative and adequate smears had been recorded at six month intervals. If the interval between the abnormal smear and the first negative and adequate smear was 18 months or over one further smear only was required after six months. All these patients were classified as having regressed and were returned to the routine screening system. Patients whose repeat smears suggested severe dyskaryosis or a more advanced lesion were referred for biopsy. Patients who had left their general practitioner during the follow up period were traced by using the NHS register at Southport and cytological follow up requested from their current general practitioner. Repeat smears screened in other laboratories, when available, were examined by the two study cytologists.

Statistical methods $-\chi^{2}$ Tests were used to compare discrete groups. A life table was constructed to estimate the cumulative probability of a biopsy being recommended for a patient after four and a half years of follow up and the $95 \%$ confidence interval calculated by the method of Armitage. ${ }^{18}$ Five year age specific incidence rates for cervical cancer in the general population were used to calculate the expected number of cases of invasive cervical cancer, ${ }^{19}$ and the probability of obtaining the observed result compared with that expected was derived from the Poisson distribution. ${ }^{20}$

\section{Results}

The source of the first abnormal smear was the general practitioner in 161 cases (24\%), a family planning clinic in 205 (31\%), a gynaecology outpatient clinic in $155(23 \%)$, an obstetric clinic in $85(13 \%)$, a genitourinary clinic in $46(7 \%)$, and a gynaecology ward in nine $(1 \%)$. Five patients $(<1 \%)$ were screened at a mobile well woman clinic. A total of 550 women $(83 \%)$ were aged less than 35 , most abnormal smears occurring in the age groups 20-24 and 25-29 (table I). This, however, reflected the age distribution of the population screened rather than the peak prevalence of early cytological abnormalities. Marital state was recorded as single in 305 cases (46\%), married in 254 $(38 \%)$, divorced or separated in $92(14 \%)$, and widowed in six (1\%). In nine women marital state was not known. Two hundred and one women $(30 \%)$ were coded as social classes I and II, $238(36 \%)$ as social class III, and $86(13 \%)$ as social class IV or V. Eighty one $(12 \%)$ women were students, and the occupational state of the remaining 60 women $(9 \%)$ was not known. Older women (aged 35-44) were more likely to have an initial smear showing moderate dyskaryosis $\left(\chi^{2}=18.5\right.$, $\mathrm{df}=9 ; \mathrm{p}<0.05)($ table I).

Forty five women $(6 \cdot 8 \%)$ had a cone biopsy recommended on the basis of an abnormal follow up smear (severe dyskaryosis suggestive of cervical intraepithelial neoplasia grade III or invasive cancer). In one patient 
TABLE III -Smear histories of five women who developed invasive cancer of cervix

\begin{tabular}{lccl}
\hline Case No & Age (years) & $\begin{array}{c}\text { Classification of dyskaryosis } \\
\text { in initial smear }\end{array}$ & \multicolumn{1}{c}{$\begin{array}{c}\text { Classification of repeat smears (time after previous } \\
\text { smear in months) }\end{array}$} \\
\hline 1 & 22 & Mild & $\begin{array}{l}\text { Mild (3), cervical intraepithelial neoplasia grade III (7), } \\
\text { invasive }(<1) \\
\text { Mild (13), mild (6), inflammatory (6), inflammatory (6), } \\
\text { cervical intraepithelial neoplasia grade III (7) }\end{array}$ \\
2 & 29 & Mild & $\begin{array}{l}\text { Mild (21), invasive (13) } \\
\text { Cancer (1 week) } \\
\text { Cancer (34) }\end{array}$ \\
4 & 34 & Mild & Inflammatory \\
5 & 53 & Mild & \\
\hline
\end{tabular}

*Smear coded as inadequate.

TABLE IV-Outcome in patients with initial mild dyskaryosis by classification of dyskaryosis in first repeat smear (excludes 68 patients with no follow up)

\begin{tabular}{lcccc}
\hline Classification of first repeat smear & $\begin{array}{c}\text { Recommended } \\
\text { for biopsy }\end{array}$ & Regressed & Others $^{\star}$ & Total \\
\hline Negative & 3 & 69 & 84 & 156 \\
Borderline or inflammatory & 2 & 9 & 31 & 42 \\
Persistent mild & 19 & 18 & 92 & 129 \\
Moderate & 4 & 3 & 16 & 23 \\
Severe & 6 & 99 & 223 & 356 \\
\hline Total & 34 & & & \\
\hline
\end{tabular}

$\star$ Patient still being followed up, or defaulted.

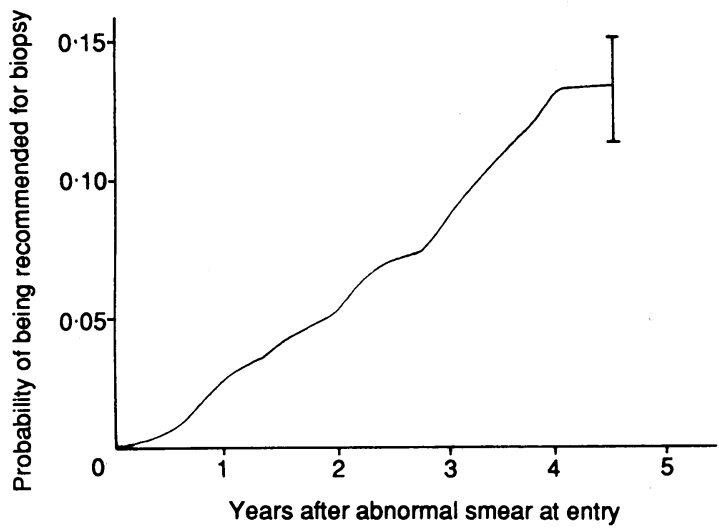

Cumulative probability of women with dyskaryosis in cervical smears subsequently being recommended for biopsy. Bars are $95 \%$ confidence intervals

cervical intraepithelial neoplasia grade III was reported in a biopsy specimen after dilatation and curettage two years after a negative smear. Table II shows the histological findings in the 45 women recommended for a biopsy. The mean interval from the abnormal smear at entry to the patient having a biopsy recommended or performed was 27 months, with a range of one week (in a patient with invasive cancer whose smear at entry showing inflammatory dyskaryosis was followed four days later by a smear at another hospital showing invasive cancer) to 48 months. The figure shows the probability over the follow up period of a patient being recommended for a biopsy. The cumulative probability after four and a half years was $14 \%$ (95\% confidence interval $12 \%$ to $15 \%$ ).

Five cases of invasive cervical cancer were observed as compared with 0.083 expected (background annual rate $0.07 / 1000 ; p<0.0001)$. This excess risk remained highly significant even when a patient (referred to above) with cervical cancer diagnosed one week after a smear at entry showing inflammatory dyskaryosis (presumed false negative) was excluded. Table III shows the smear histories of the five women.

At the end of the four and a half year follow up 187 patients $(28 \%)$ were still under cytological surveillance either because of persistent dyskaryosis or because of having fewer than the required number of negative smears. One hundred and fifty seven patients (24\%) had smears fulfilling the criteria for reversion to normal.

A main problem in this study was the high mobility of the population, both inside and out of the north London area. A further difficulty was in maintaining regular follow up of patients. Despite intensive efforts to trace and follow up the study population, 119 patients $(18 \%)$ had no repeat smears after the smears at entry. The initial smears from these patients were classified as borderline or inflammatory in 46 cases, mild dyskaryosis in 68 , and moderate dyskaryosis in five. A further 149 patients, though followed up at least once, had no record of a repeat smear three months after the last date specified by the laboratory. The last smears from these patients were classified as negative in 91 , borderline or inflammatory in six, mild dyskaryosis in 49, and moderate dyskaryosis in three.

Eight patients had a hysterectomy for reasons not associated with cytological abnormalities.

Patients whose smears at entry showed moderate dyskaryosis were more likely to have a biopsy performed ( $8 / 39$ cases; $21 \%$ ) compared with those whose smears showed mild dyskaryosis $(34 / 424 ; 8 \%)$ or borderline or inflammatory changes $(4 / 203 ; 2 \%)\left(\chi^{2}=\right.$ $19.7, \mathrm{df}=2 ; \mathrm{p}<0.001)$. The relative risk of being recommended for a biopsy conferred by a smear showing moderate dyskaryosis at any time compared with other classes of dyskaryosis was $7 \cdot 7$ (95\% confidence interval 4.9 to 12.9 ). The outcome in patients whose initial smears showed mild dyskaryosis was significantly influenced by the finding in the first repeat smear (table IV). Of 356 first repeat smears in such patients, six (2\%) showed severe dyskaryosis suggestive of cervical intraepithelial neoplasia grade III, $23(6 \%)$ moderate dyskaryosis, 129 (36\%) persistent mild dyskaryosis, and $42(12 \%)$ borderline or inflammatory changes and $156(44 \%)$ were negative. Patients whose repeat smears showed persistent mild dyskaryosis were significantly more likely to have a biopsy performed $(19 / 129 ; 15 \%)$ and less likely to show regression (18/ $129 ; 14 \%$ ) compared with patients whose repeat smears were negative $(3 / 156$ and $69 / 156 ; 2 \%$ and $44 \%)\left(\chi^{2}=\right.$ $38.3, \mathrm{df}=2 ; \mathrm{p}<0.001)$. We also examined the proportion of dyskaryotic smears found a minimum of three months after a negative smear classified as adequate or inadequate. Dyskaryosis was subsequently recorded in a greater proportion of women after a single negative inadequate smear $(22 / 55)$ than after an adequate negative smear $(61 / 316)\left(\chi^{2}=11 \cdot 6, \mathrm{df}=1 ; \mathrm{p}<0.001\right)$.

\section{Discussion}

The cumulative probability of a woman with dyskaryosis detected in a cervical smear being recommended for a biopsy after four and a half years was $14 \%$ ( $95 \%$ confidence interval $12 \%$ to $15 \%$ ) Interpretation of the results in terms of natural course, however, must be cautious. Many workers have used the word "progress" to describe the change to a more severe lesion, but there are objections to this term as the pre-existence of a more severe lesion can never be excluded. A quarter of women who required a biopsy were identified within 12 months of the initial abnormal smear. Apart from one patient with invasive cancer detected one week after a smear showing inflammatory dyskaryosis there was no way of determining in how many the more severe abnormality was already present. Probably we have underestimated the risk of a biopsy being required as the women who defaulted included those at higher risk; 15 had an initial smear showing moderate dyskaryosis and 49 had at least two smears showing mild dyskaryosis.

The finding of a significant excess of invasive cancers in a series of women with dyskaryosis confirms that this is a high risk population. Despite regular cytological follow up two women developed invasive cancer. In a further two cases the recommended interval to repeat the smear was exceeded (by seven and 31 months), and in one patient who was diagnosed immediately it is presumed that the smear at entry was a false negative. 
These findings indicate that the management of patients found to have a dyskaryotic smear does not protect completely against subsequent invasive cancer.

Three of the five cases of invasive cancer were in women aged under 35 . Over the past decade mortality and incidence rates for cancer of the cervix have increased in younger women, although the rates in those under 25 are still very low compared with those in older women..$^{21}$ Robertson et al described 10 cases of invasive cancer of the cervix occurring in their study of 1781 women identified with a dyskaryotic smear over 20 years. ${ }^{12}$ It was not clear, however, whether those cases represented a significant excess or the number to be expected on the basis of the background rate or, indeed, a deficit as no statistical criteria were applied.

Our criteria for reversion to normal were more rigorous than those reported by some workers. We checked on the subsequent outcome of these patients after a further two years. Fifty five of the 157 patients classified as having reverted to normal $(35 \%)$ had a record of a subsequent smear. In 53 out of these 55 women this smear was reported as negative after a mean of 17 months (range 1-47 months). Twenty one of these 53 patients had two or more negative smears subsequently. This suggests that when several adequate repeat smears remain negative over more than 18 months regression may be real rather than apparent. Almost two thirds of women, however, had no further smears, and there may have been a selection bias in the $35 \%$ who continued to have smears despite being discharged.

The poor reliability of a single negative smear to suggest apparent regression is shown by the finding that $22 \%$ of these women $(83 / 371)$ had a follow up smear showing dyskaryosis. When the negative smear was also inadequate this figure increased to $40 \%(22 / 55)$. Our study clearly indicates the importance of following up women with dyskaryotic smears and especially those with a smear showing moderate dyskaryosis or two smears showing mild dyskaryosis. We do not wish to make recommendations about the exact details of how this follow up should be conducted in the current state of knowledge. There is no experimental evidence that prognosis is improved by colposcopic compared with cytological surveillance. We endorse the inter-

collegiate working party's proposal for a randomised controlled trial to examine costs and benefits of these two alternatives.

We thank Mike Everett and Jess Bimrah for computing, the staff of the cytology laboratory, and all medical staff whose patients contributed to the study. The study was supported. by a grant from the North East Thames Regional Health Authority.

1 Singer A. The abnormal cervical smear. Br Med f1986;293:1551-6.

2 Fox H. Cervical smears: new terminology and new demands. Br Med $f$ 1987;294:1307-8.

3 Campion MJ, Singer A, Mitchell HS. Complacency in diagnosis of cervical cancer. Br Med F 1987;294:1337-9.

4 Intercollegiate Working Party on Cervical Cytology Screening. Report. London: Royal College of Obstetricians and Gynaecologists, 1987.

5 Nasiell K, Nasiell $M$, Vaclavinkova V. Behavior of moderate cervical dysplasia during long term follow up. Obstet Gynecol 1983;61:609-14

6 Barron BA, Richart RM. Statistical model of the natural history of cervical carcinoma. II. Estimates of the transition time from dysplasia to carcinoma in situ. I Natl Cancer Inst 1979;45:1025-30.

7 Hulka BS. Cytologic and histologic outcome following an atypical cervical smear. Am 7 Obstet Gynecol 1968;101:190-9.

8 Spriggs AL, Boddington MM. Progression and regression of cervical lesions. Review of smears from women followed without initial biopsy or treatment. f Clin Pathol 1980;33:517-22.

9 Hulka BS, Redmond CK. Factors related to progression of cervical atypias. Am f E pidemiol 1971;93:23-32.

10 Berget A. Epithelial dysplasia of the cervix uteri. Dan Med Bull 1974;21:169. 71

11 Campion MJ, McCance DJ, Cuzick J, Singer A. Progressive potential of mild cervical atypia: prospective cytological, colposcopic and virological study. Lancet 1986;ii:237-40.

2 Robertson JH, Woodend BE, Crozier EH, Hutchinson J. Risk of cervical cancer associated with mild dyskaryosis. Br Med f 1988;297:18-21.

3 Husain OAN, Butler CB, Evans LDMP, MacGregor JE, Yule R. Quality control in cervical cytology. $\mathcal{F}$ Clin Pathol 1974;27:935-44.

14 Parkin DM, Leach K, Cobb P, Clayden AD. Cervical cytology screening in two Yorkshire areas: results of testing. Public Health 1982;96:3-14.

15 Koss LG, Stewart FW, Foote FW, Jordan MJ, Bader GM, Day EM. Some histological aspects of behavior of epidermal carcinoma in situ and related lesions of the uterine cervix. Cancer 1963;16:1160-211.

16 Office of Population Censuses and Surveys. Classification of occupations. London: HMSO, 1970.

17 Bounds W, Grubb C, Metaxas N, Vessey M. A randomised comparative trial of the performance of the Ayre and the Armovical cervical spatulae. $\mathrm{Br} f$ of the performance of the Ayre a

18 Armitage P. Statistical methods in medical research. Oxford: Blackwell Scientific, 1971

19 Waterhouse JAH. Cancer handbook of epidemiology. Edinburgh: Churchill Livingstone, 1974 .

20 Pearson ES, Hartley HO. Biometrika tables for statisticians. Vol 1. Cambridge: Cambridge University Press, 1962.

21 Cook GA, Draper GJ. Trends in cervical cancer and carcinoma in situ in Great Britain. Brf Cancer 1984;50:367-75.

(Accepted 20 fuly 1990)

\section{Why costs of consultations in general practice vary}

\section{S E J Twaddle, A M D Porter, J G R Howie, J F Forbes}

Department of General Practice, University of Edinburgh, Edinburgh EH8 9DX

S E J Twaddle, MSC, research associate

A M D Porter, MPHIL, lecturer

J G R Howie, MD, professor J F Forbes, PHD, research fellow

Correspondence to: $\mathrm{Mr}$ Porter.

BrMed f 1990;301:644-5 apportioned. ${ }^{12}$
Fixed costs of general practitioners' services include the costs of staff (which depend on their number and skills), investment in practice premises, and equipment. In the short term general practitioners can more easily exercise control over variable costs (those of prescribing, investigation, and referral) arising from their preferred or personal style of consultation. We present minimum estimates of the variable costs associated with prescribing, investigation, and referral behaviour during consultations in the surgery and show that the incentive for fund holding doctors to change their behaviour will depend on how costs of prescribing and referral are calculated and

\section{Patients, methods, and results}

As part of a one year study of workload (1987-8) 85 principals in general practice in Lothian provided details of consultations in their surgeries; the study was reported in detail previously. ${ }^{3}$ Information on prescribing (excluding repeat prescriptions), requests for radiography and selected diagnostic tests, and outpatient referral was collected for 21707 consultations. The average cost of prescriptions, radiography, laboratory requests (bacteriology, virology, biochemistry, haematology), and outpatient referral (one outpatient attendance) was obtained from the Scottish Health Service's financial accounts. Capital costs were not included in these estimates of average cost. Total variable costs, representing the sum of these discretionary items of service, were calculated and expressed per 100 consultations, which corresponded with the average weekly number of consultations in the surgery reported by the doctors (table).

The mean (SD) overall variable cost per 100 consultations was $£ 444$ (88) (range $£ 329-735$ ). Differences in costs were largely explained by the underlying variation in prescribing behaviour. The number of prescriptions per 100 consultations ranged from 36 to 93 (mean 67 (14)). A ninefold difference in outpatient referral (mean 6 (2)) also contributed to the observed variation in cost. Differences in the style of practice, as measured by requests for diagnostic tests and radiography, were less important determinants of overall differences in cost. 